\title{
Effect of Intermittent Serial Casting on Equinus Ankle Deformity in Children with Hemiplegic Cerebral Palsy
}

\author{
YASSER M. ABD EL-MONEM, M.Sc.*; ELHAM E. SALEM, Ph.D.*; MOHAMED I. EL-ASSAL, Ph.D.* and \\ MAHMOUD A. MAHRAN, M.D.** \\ The Department of Pediatrics, Faculty of Physical Therapy, Cairo University* and \\ The Department of Orthopedic Surgery, Faculty of Medicine, Ain Shams University**
}

\begin{abstract}
Background: Equinus is the most common problem in ambulatory children with spastic hemiplegic cerebral palsy, which results in an unstable and inefficient gait pattern. Without proper management at an early stage, it can lead to permanent foot deformities.
\end{abstract}

Aim of Study: The aim of this study was to evaluate the effect of serial casting on ankle range of motion, tone of the calf muscle and ankle kinematics during gait in children with spastic hemiplegic cerebral palsy.

Material and Methods: Twenty-five spastic hemiplegic cerebral palsy children of both sexes ( 15 boys and 10 girls) participated in this study. Patients were selected at level I according to Gross Motor Function Classification System and the degree of spasticity ranged from 2 to 3 according to Modified Ashworth Scale with true equinus, with their mean age were $4.8 \pm 0.8$ years. They were randomly assigned to two groups. The first group, 12 children, Group (A) who received a selected physical therapy program once a day $/ 3$ times a week for three successive weeks; while the second group, 13 children, Group (B) who received three consecutive casts for five days each and removed in the last two days in each week to conduct the same selected physical therapy program which conducted for the Group (A). Ankle range of motion was assessed by electronic goniometer, calf muscle spasticity was assessed by modified ashworth scale and ankle kinematics during gait was assessed by observational gait scale.

Results: The results of the present study revealed that Group (B) showed statistically significant improvement in ankle range of motion, tone of calf muscle and ankle kinematics during gait ( $p=0.0001$ for all) than those of the Group (A)

Conclusion: Serial casting of equinus ankle deformity could improve ankle range of motion, tone of calf muscle and ankle kinematics during gait in children with spastic hemiplegic cerebral palsy.

Key Words: Cerebral palsy - Equinus foot - Hemiplegia Serial casting-Spasticity.

Correspondence to: Dr. Yasser M. Abd El-Monem The Department of Pediatrics, Faculty of Physical Therapy, Cairo University

\section{Introduction}

HEMIPLEGIA in infants and children is a type of CP results from damage to the hemisphere of the brain that controls muscle movement. This damage may occur before, during or shortly after birth. In children with hemiplegia the paralysis in body occurs on the side opposite the affected part of the brain which means if the right side of the children brain injured the paralysis will be on the left side of the child's body [1]

The majority of children with hemiplegia are able to walk without restrictions but more advanced gross motor skills are often jeopardized. Although children with hemiplegia are able to walk without external support they have abnormal gait patterns including asymmetry between the affected and unaffected side [2]. In children with Hemiplegic Cerebral Palsy (HCP) spasticity is not only the most common motor disorder but also the main cause of slowly developing secondary problems like contractures and bony deformities [3]

Equinus, defined as a sagittal plane ankle deformity with increased Plantarflexion (PF) at the ankle, very limited motion in subtalar joint and standing or walking with increased weight bearing on the metatarsal heads [4]. An equinus foot in children with HCP is caused by spasticity or shortening of the gastocnemius-soleus muscle complex or a combination of these two components. Initially, it appears to be a dynamic phenomenon, secondary to a central nervous system lesion. As the child grows, the progressive shortening of the calf muscles secondary to spasticity develop to such a significant degree that the contracture may require surgical lengthening of the muscle but since children's feet are relatively flexible and adaptable, 
non-operative management is typically used as a first course of treatment [5]

The treatment program for a child with $\mathrm{HCP}$ may include different options: Exercises, bracing, casting, oral medications and orthopedic surgery. Because of the limited efficiency of "traditional" treatments as exercises and bracing, a wide range of complementary and alternative therapies are used for muscle tone and Range of Motion (ROM) management [6,7]. Serial casting is the use of a series of progressive muscle stretching casts to increase muscle length using prolonged low load stress to contracted tissue [8]

\section{Material and Methods}

The study was designed as a prospective, randomized, pre-post-test, controlled trial. This study was conducted in the outpatient clinics of Naser General Hospital and The Faculty of Physical Therapy from January 2018 to June 2018. Written informed consent was taken from parents or legal guardians of all participants that was approved by the Research Ethical Committee of The Faculty of Physical Therapy Cairo University. Thirty children from both sexes (15 boys and 15 girls) with a diagnosis of spastic hemiplegic cerebral palsy were selected according to the following criteria: Being 3 to 6 years old, having a Modified Ashworth Scale score of 2 or 3 in the plantar flexor muscle complex, having a Gross Motor Functional Classification System level I, having a true equinus, classified as type 2 gait pattern described by Winters et al., (significant plantarflexion throughout the gait cycle with full extension or recurvatum of knee in stance phase), and they were able to follow instructions given to them during assessment and treatment. Patients with bony joint limitation, previous surgeries (tendon lengthening), received Botulinumtoxin A injections in the last six months, or with apparent equinus as a compensation for knee or hip flexion while dorsiflexion range is preserved at the lower extremity to be treated or casted were excluded.

The children were randomly assigned using a computer program into two groups of equal numbers. The Group (A) included fifteen children (n $=15$ ) received a selected physical therapy program once a day/3 times a week for three successive weeks mainly consisted of stretching and strengthening exercises, weight bearing, balance, proprioception, and ambulation training. And fifteen children served as Group (B) $(n=15)$ additionally received three consecutive casts applied for five days each and removed in the last two days in each week to conduct the same selected physical therapy program which conducted for the Group (A). The casting consisted of short leg casts applied while the child in prone position with the knee flexed to 90 degrees and the ankle dorsiflexed to maximal attainable dorsiflexion and held in the neutral hind foot position to prevent hypermobility of the subtalar joint. Three participants dropped out of the Group (A) with no reason given and two participants dropped out of the Group (B) due to the appearance of swelling and skin allergic reaction to the cast material.

Evaluation of children in both groups was performed before as well as after three successive weeks of intervention by using electronic goniometer [10] to assess ankle ROM, Modified Ashworth Scale (MAS) [11] to assess calf muscle tone and Observational Gait Scale (OGS) [12] to assess ankle kinematics during gait.

The ankle ROM angle was measured by BASELINE electronic goniometry with the "neutralnull" method (dorsiflexion angle over the neutral position was counted in positive degrees, under the neutral in negative degrees). The child was placed in a supine position with knee in extension and placing the ankle in planterflexion position and move to a position of maximal dorsiflexion and joint angle taken from the digital display of the goniometer. Muscle tone of the ankle plantar flexor was measured by MAS. The child was placed in a supine position, head in neutral position with knee in extension and placing the ankle in the maximally planter flexion position and move to a position of maximal dorsiflexion over one second (count one thousand one). The observational gait scale was used to analyze typical walk viewed on split-screen video in slow motion. The children were instructed to walk and videos are taken from the side, only five sections were tested to evaluate ankle kinematics and knee position in relation to ankle (initial foot contact, foot contact at mid stance, timing of heel rise, knee position in mid stance, degree of change) with a total score of 14 on each limb.

\section{Statistical analysis:}

Descriptive statistics and $t$-test was conducted for comparison of age, weight and height, between both groups. Chi squared test was conducted for comparison of distribution of sex, spasticity grades between groups. $t$-test was conducted for comparison of ankle ROM and OGS between groups. Test of marginal homogeneity was conducted for com- 
parison of between pre and post-treatment spasticity grades in each group. Paired $t$-test was conducted for comparison between pre and post-treatment measurements of ankle ROM and OGS in each group. The level of significance for all statistical tests was set at $p<0.05$. All statistical measures were performed through the Statistical Package for Social Studies (SPSS) Version 19 for windows.

\section{Results}

Twenty-five out of thirty selected children with HCP completed the trial. Patients were randomly ordered into two groups. The Group (A), included twelve children $(n=12)$, who received a selected physical therapy program once a day/3 times a week for three successive weeks. And the Group (B), included thirteen children $(n=13)$, who received the same selected physical therapy program in addition to serial casting. There was no significant difference between groups in the mean age (y), weight $(\mathrm{kg})$ and height $(\mathrm{cm}),(p>0.05)$ (Table 1).
There was no significant difference in the ankle ROM, the distribution of spasticity grades of calf muscle tone, and the total score of OGS ( $p=0.64$, $p=0.44, p=0.64$ ) respectively, between the (A) and (B) groups pre-treatment. In Group A, there were a significant increase in the mean values of ankle ROM and the total score of OGS post-treatment when compared with its corresponding values measured at pre-treatment ( $p=0.0001$ for both). There was no significant difference in posttreatment evaluation of calf muscle tone in Group (A) when compared with its corresponding value measured at pre-treatment $(p=1)$. In Group B, there were a significant differences in ankle ROM, degree of calf muscle spasticity, and total score of OGS ( $p=0.0001$ for all) in post-treatment mean values when compared with its corresponding values measured at pre-treatment. The average changes in ROM, MAS, and OGS of the casting Group (B) were significantly higher than those of the group (A) post-treatment ( $p=0.0001$ for all) (Tables 2-4).

Table (1): Descriptive statistics and $t$-test for comparing the mean age, weight and height of the control and study group.

\begin{tabular}{lllllll}
\hline & $\begin{array}{c}\text { Control group } \\
(\mathrm{n}=12) \\
\mathrm{X} \pm \mathrm{SD}\end{array}$ & $\begin{array}{c}\text { Study group } \\
(\mathrm{n}=13) \\
\mathrm{X} \pm \mathrm{SD}\end{array}$ & MD & $\begin{array}{c}t- \\
\text { value }\end{array}$ & $\begin{array}{c}p- \\
\text { value }\end{array}$ & Sign \\
\hline Age (years) & $4.85 \pm 0.73$ & $4.8 \pm 0.8$ & 0.05 & 0.18 & 0.85 & $\mathrm{SN}$ \\
Weight $(\mathrm{kg})$ & $16.79 \pm 2.85$ & $16.07 \pm 2.78$ & 0.72 & 0.63 & 0.53 & $\mathrm{SN}$ \\
Height $(\mathrm{cm})$ & $102.33 \pm 6.38$ & $101.38 \pm 7.62$ & 0.95 & 0.33 & 0.74 & $\mathrm{SN}$ \\
\hline
\end{tabular}

Table (2): Comparison between post-treatment mean values of ankle ROM of control and study groups.

\begin{tabular}{lccccccc}
\hline & $\begin{array}{c}\text { Control group } \\
\mathrm{X} \pm \mathrm{SD}\end{array}$ & $\begin{array}{c}\text { Study group } \\
\mathrm{X} \pm \mathrm{SD}\end{array}$ & $\mathrm{MD}$ & $\begin{array}{c}\% \text { of } \\
\text { improvement }\end{array}$ & $\begin{array}{c}t- \\
\text { value }\end{array}$ & $\begin{array}{c}p- \\
\text { value }\end{array}$ & Sig. \\
\hline Ankle ROM (degrees) & $3.83 \pm 4.3$ & $15.84 \pm 4.23$ & -12.01 & 313.57 & -7.02 & 0.0001 & $\mathrm{~S}$ \\
\hline
\end{tabular}

Table (3): The frequency distribution and chi squared test for comparison of spasticity grades distribution between both groups (control and study).

\begin{tabular}{lllcrr}
\hline & Control group & Study group & $\chi^{2}$ value & $p$-value & Sig. \\
\hline Grade I & $0(0 \%)$ & $5(38.5 \%)$ & 25 & 0.0001 & $\mathrm{~S}$ \\
Grade I+ & $0(0 \%)$ & $8(61.5 \%)$ & & \\
Grade II & $5(41.7 \%)$ & $0(0 \%)$ & & \\
Grade III & $7(58.3 \%)$ & $0(0 \%)$ & & \\
\hline
\end{tabular}

Table (4): Comparison between post-treatment mean values of total score of OGS of control and study groups.

\begin{tabular}{|c|c|c|c|c|c|c|c|}
\hline & $\begin{array}{c}\text { Control group } \\
\quad \mathrm{X} \pm \mathrm{SD}\end{array}$ & $\begin{array}{c}\text { Study group } \\
X \pm S D\end{array}$ & MD & $\begin{array}{c}\% \text { of } \\
\text { improvement }\end{array}$ & $\begin{array}{c}t- \\
\text { value }\end{array}$ & $\begin{array}{c}p- \\
\text { value }\end{array}$ & Sig. \\
\hline Total score of OGS & $7.16 \pm 1.4$ & $10.07 \pm 1.38$ & -2.91 & 40.62 & -5.22 & 0.0001 & $\mathrm{~S}$ \\
\hline
\end{tabular}




\section{Discussion}

Equinus is the most common gait abnormalities found in children with hemiplegic gait (64\%) [13] There is general agreement that surgery should be avoided until gait has matured as early surgical interventions have a higher risk of failure and relapse. Besides, repeated muscle and tendon surgeries should be avoided to prevent weakness. An early, non-operative, comprehensive, and combined treatment approach including both pharmacological and rehabilitative interventions are needed in these children to improve the overall condition, and prevent the development of secondary problems as soft tissue contractures and skeletal deformities $[4,14]$. Serial casting has become an increasing integral part of treatment of children with cerebral palsy, and has a long history as an adjunct to physiotherapy in the management of children with cerebral palsy [15]. Strength training in children with CP registered significant improvements on strength, gait and gross motor function, also stretching performed either by the clinician, or children themselves is used as treatment modality to increase joint range of motion $[\mathbf{1 6 , 1 7 ]}$ with increase in range of motion and reduction of spasticity we could improve ambulatory status of our children to a great extent [18]. Kay et al., [19] suggested that serial casting alone is preferable for the treatment of equinus deformity in children with $\mathrm{CP}$.

The results of this prospective, randomized, controlled clinical study showed that a well-defined population of children who have spastic equinus foot due to HCP might have additional benefits when physical therapy was combined with a treatment of intermittent serial casting. These intermittent serial casting periods might provide additional benefits on improvement in ROM, reduction of spasticity, and improvement in ankle kinematic during gait. The results of the present study revealed that there were a significant improve in ankle joint ROM, reduction of calf muscle tone and also improve of ankle kinematic during gait ( $p=0.0001$ for all) between Group (A) and Group (B) in favor to the Group (B).

The result of current study in line with those of Corry et al. [20], and Glanzman et al., [15] who revealed that casting demonstrated a significant robust impact on range of motion, and there is a significant tone reductions when performed to children with CP. Also studies of Gajdosik [21], and Al-Oraibi et al., [10] found that casting maintains muscles in tonic stretch to increase elasticity and to affect changes in characteristics of muscleligament parts which increasing the joint's range of motion, muscle extensibility, and functional mobility. A published study by Dursun et al., [3] reported additional benefits not only in spasticity and passive ROM but also in gait function when BTX-A injections and physical therapy were combined with a treatment of intermittent serial casting in children who have spastic equinus foot due to CP.

In conclusion, serial casting of equinus foot was shown effective at improving ankle range of motion, tone of calf muscle and ankle kinematics during gait in spastic hemiplegic cerebral palsy children.

Recommendations for further research include using of above knee serial casting in spastic hemiplegic cerebral palsy with equinus with knee flexion and exploring the effects of serial casting on fixed equinus (contracture).

\section{References}

1- STRAUB K. and OBRZUT J.E.: Effects Of Cerebral Palsy On Neuropsychological Function. Journal Of Developmental And Physical Disabilities, 21, 153, 2009.

2- LEDEBT A., BECHER J., KAPPER J., ROZENDAAL R.M., BAKKER R., LEENDERS I.C. and SAVELSBERGH G.J.: Balance Training With Visual Feedback In Children With Hemiplegic Cerebral Palsy: Effect On Stance And Gait. Motor Control, 9: 468-459, 2005.

3- DURSUN N., GOKBEL T., AKARSU M. and DURSUN E.: Randomized controlled trial on effectiveness of intermittent serial casting on spastic equinus foot in children with cerebral palsy after botulinumtoxin-A treatment. American Journal of Physical Medicine \& Rehabilitation, 96: 221-5, 2017.

4- CHEN W., LIU X., PU F., YANG Y., WANG L., LIU H. and FAN Y.: Conservative treatment for equinus deformity in children with cerebral palsy using an adjustable splintassisted ankle-foot orthosis. Medicine, 96, 2017.

5- SÄTњÄ H., PIETIKÄINEN T., IISALO T., LEHTONENRÄTY P., SALO M., HAATAJA R., KOIVIKKO M. and AUTTI-RÄMÖ I.: Botulinum toxin type A injections into the calf muscles for treatment of spastic equinus in cerebral palsy: A randomized trial comparing single and multiple injection sites. American Journal of Physical Medicine \& Rehabilitation, 87: 386-94, 2008.

6- FISHER C. and NEWTON B.: Pediatric Constraint Induced Movement Therapy Protocols for Hemiplegia, 2016.

7- KACHMAR O., VOLOSHYN T. and HORDIYEVYCH M.: Changes In Muscle Spasticity In Patients With Cerebral Palsy After Spinal Manipulation: Case Series. Journal of Chiropractor Medicine, 15: 299-304, 2016.

8- BOOTH M.Y., YATES C.C., EDGAR T.S. and BANDY W.D.: Serial casting vs combined intervention with botulinumtoxin A and serial casting in the treatment of spastic equinus in children. Pediatric Physical Therapy, 15: 216$20,2003$. 
9- WINTERS T.F., GAGE J.R. and HICKS R.: Gait patterns in spastic hemiplegia in children and young adults. Journal of Bone and Joint Surgery (Am.), 69: 437-41, 1987.

10- AL-ORAIBI S., TARIAH H.A. and ALANAZI A.: Serial casting versus stretching technique to treat knee flexion contracture in children with spina bifida: a comparative study. Journal of Pediatric Rehabilitation Medicine, 6: 147-53, 2013

11- BOHANNON R.W., LARKIN P.A., SMITH M.B. and HORTON M.G.: Relationship Between Static Muscle Strength Deficits And Spasticity In Stroke Patients with Hemiparesis. Physical Therapy, 67: 1068-71, 1987.

12- ARAÚJO P., KIRKWOOD R. and FIGUEIREDO E.: Validity And Intra-Rater And Inter-Rater Reliability Of The Observational Gait Scale For Children With Spastic Cerebral Palsy. Brazilian Journal of Physical Therapy, 13: 267-73, 2009.

13-WREN T.A., RETHLEFSEN S. and KAY R.M.: Prevalence of specific gait abnormalities in children with cerebral palsy: Influence of cerebral palsy subtype, age, and previous surgery. Journal of Pediatric Orthopaedics, 25 (1): 79-83, 2005.

14- MOLENAERS G., VAN-CAMPENHOUT A., FAGARD K., De CAT J. and DESLOOVERE K.: The use of botulinumtoxin $\mathrm{A}$ in children with cerebral palsy, with a focus on the lower limb. Journal of Children's Orthopaedics, 4: 183-95, 2010.

15- GLANZMAN A.M., KIM H., SWAMINATHAN K. and
BECK T.: Efficacy Of Botulinum Toxin A, Serial Casting, And Combined Treatment For Spastic Equinus: A Retrospective Analysis. Developmental Medicine And Child Neurology, 46: 807-11, 2004.

16- LEE J.H., SUNG I.Y. and YOO J.Y.: Therapeutic effects of strengthening exercise on gait function of cerebral palsy. Disability and Rehabilitation, 30: 1439-44, 2008.

17- THEIS N., KORFF T., KAIRON H. and MOHAGHEGHI A.A.: Does acute passive stretching increase muscle length in children with cerebral palsy? Clinical Biomechanics, 28: 1061-7, 2013.

18- JAIN S., MATHUR N., JOSHI M., JINDAL R. and GOENKA S.: Effect Of Serial Casting In Spastic Cerebral Palsy. The Indian Journal of Pediatrics, 75: 997-1002, 2008.

19- KAY R.M., RETHLEFSEN S.A., FERN-BUNEO A., WREN T.A. and SKAGGS D.L.: Botulinumtoxin as an adjunct to serial casting treatment in children with cerebral palsy. Journal of Bone and Joint Surgery, 86: 2377-84, 2004.

20- CORRY I., COSGROVE A., DUFFY C., MCNEILL S., TAYLOR T. and GRAHAM H.: Botulinumtoxin A compared with stretching casts in the treatment of spastic equinus: A randomized prospective trial. Journal of Pediatric Orthopaedics, 18: 304-11, 1998.

21- GAJDOSIK R.L.: Passive extensibility of skeletal muscle: Review of the literature with clinical implications. Clinical Biomechanics, 16: 87-101, 2001. 


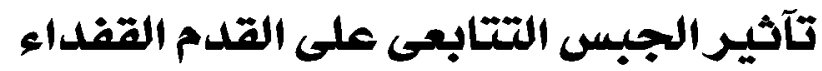

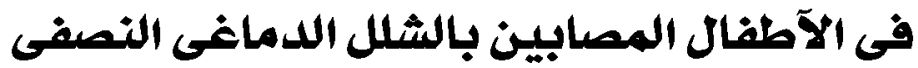

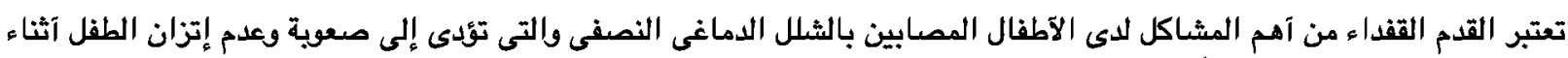

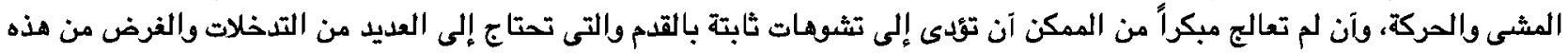

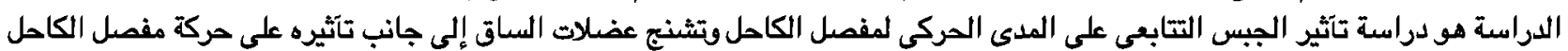

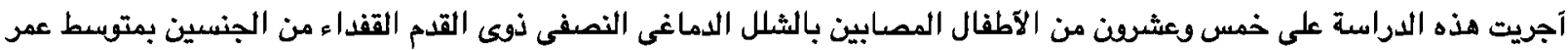

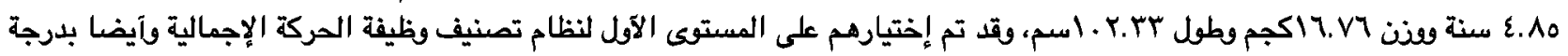

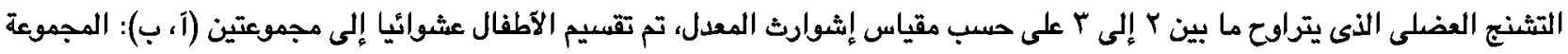

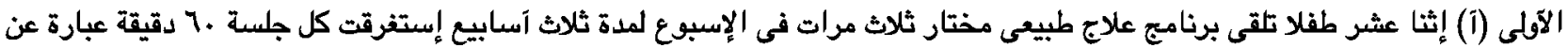

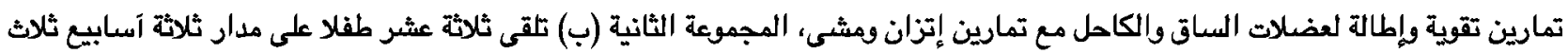

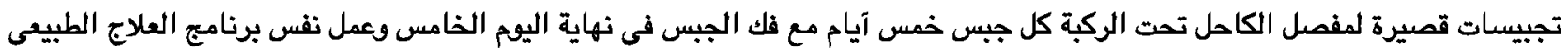
المختار الذى تم عمله للمجموعة (آ) لمدة يومين ثم التجبيس مرة آخرىى.

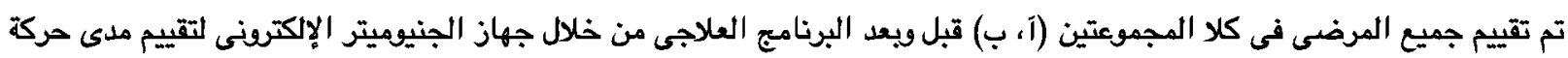

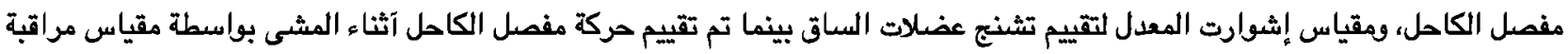

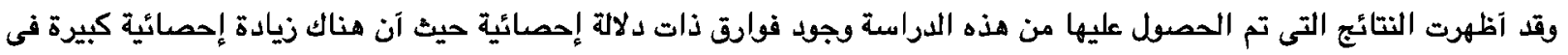

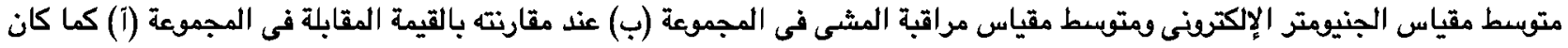

هناك إنخفاض إحصائى كبير فى قيمة مقياس إشوارت المعدل في المجموعة (ب) عند مقارنته بالقيمة لها في المجموعة (آ).

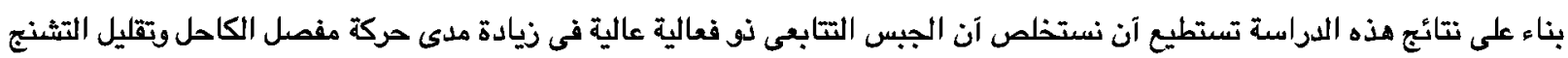

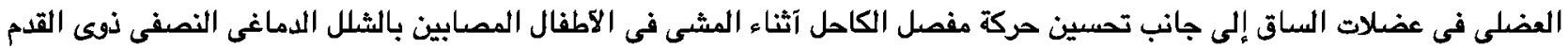

